\title{
AVANÇO DAS FERRAMENTAS UTILIZADAS NO ENSINO DO DESENHO TÉCNICO CIVIL
}

\author{
ADVANCING OF TOOLS USED IN TEACHING CIVIL TECHNICAL DRAWING \\ Humberto Mycael Mota Santos ${ }^{1}$, Donisete de Oliveira ${ }^{2}$, Luiz Augusto Ferreira de Campos Viana ${ }^{3}$
}

DOI: 10.37702/REE2236-0158.v40p102-113.2021

\begin{abstract}
RESUMO
O mercado de trabalho está sempre passando por diversas modificações impulsionadas pelas tecnologias. No ramo da construção civil, estas são observadas frequentemente até mesmo na elaboração de projetos com a criação de novos softwares. As instituições de ensino devem estar atentas a essas mudanças, pois os alunos devem concluir seus cursos preparados para enfrentar o mercado de trabalho. Pensando nisso, observou-se o avanço das ferramentas utilizadas na elaboração dos desenhos técnicos civis, desde os desenhos com o auxílio da prancheta até os softwares mais modernos e importantes para o desenvolvimento profissional. Logo, o presente trabalho apresenta as principais ferramentas usadas no ensino do desenho técnico civil, prancheta, sistema CAD e BIM, além dos resultados de uma pesquisa de campo realizada com estudantes do curso técnico em edificações sobre as novas ferramentas de desenho e a implantação do ensino do sistema BIM, bem como recomendações para inserir o sistema BIM no âmbito escolar.
\end{abstract}

Palavras-chave: ensino; desenho técnico civil; BIM.

\begin{abstract}
The labor market is always undergoing several changes driven by technologies. In the field of civil construction, it is often observed even in the elaboration of projects with the creation of new software. Educational institutions should be aware of these changes, as students must complete their courses prepared to face the job market. With this in mind, we observed the advancement of tools used in the preparation of civil technical drawings, ranging from drawings with the aid of the drawing board to the most modern and important software for professional development. Therefore, the present work presents the main tools used in the teaching of civil technical drawing, drawing board, CAD and BIM system, in addition to conducting field research with students of the technical course in buildings on the new drawing tools and the implementation of the teaching of the BIM system, as well as recommendations for inserting the BIM system in the school environment.
\end{abstract}

Keywords: teaching; civil technical drawing; BIM.

\section{INTRODUÇÃO}

A indústria da construção civil é uma das que mais se atualiza no mundo com o avanço da tecnologia, sendo necessária a elaboração de projetos em menor tempo e otimizados. Devido a essas necessidades, ferramentas para o desenvolvimento de desenho técnico civil foram evoluindo com o passar do tempo, indo desde a utilização primitiva de pranchetas,

\footnotetext{
${ }^{1}$ Professor do Instituto Federal de Pernambuco (IFPE) - Campus Caruaru; humbertomycael@gmail.com

${ }^{2}$ Pós-Graduando em Docência pelo Instituto Federal de Minas gerais (IFMG) - Campus Avançado Arcos; donnybrazil@hotmail.com

${ }^{3}$ Professor do Instituto Federal de Minas Gerais (IFMG) - Campus Avançado Arcos; luiz.viana@ifmg.edu.br
} 
avançando para software em ambiente CAD (Desenho Assistido por Computador) até chegar, atualmente, na tecnologia BIM (Building Information Modeling) ou Modelagem da Informação da Construção.

A tecnologia BIM já é consolidada na Europa, nos Estados Unidos e na Ásia como preferência no desenvolvimento de desenho técnico civil (BAIA, 2015). Haja vista o potencial dessa nova tecnologia, o Governo Federal oficializou, por meio da publicação do Decreto $\mathrm{n}^{\mathrm{o}} 9.377$ (BRASIL, 2018a), a Estratégia Nacional de Disseminação do Building Information Modeling (BIM) Estratégia BIM BR, cuja finalidade é promover condições para o investimento na metodologia BIM e sua difusão no Brasil.

A estratégia BIM BR propõe a utilização $\mathrm{e}$ a exigência do BIM em três fases, sendo a primeira delas a partir de janeiro de 2021, quando será exigido o BIM na elaboração dos modelos de engenharia e arquitetura relativos às disciplinas de Estrutura, de Hidráulica, de Elétrica e de AVAC (Aquecimento, Ventilação e Ar-condicionado), na detecção de interferências e na revisão dos modelos de arquitetura e de engenharia, na extração de quantitativos e na geração de documentação gráfica, a partir desses modelos (BRASIL, 2018b).

Logo, observa-se que a partir de tal data será exigido o uso da tecnologia BIM em algumas situações. Sendo assim, torna-se de fundamental importância que os alunos saiam da academia com esse conhecimento.

Para os profissionais conseguirem se manter no mercado de trabalho é essencial manusearem as novas tecnologias. Com relação à área de projeto, é recomendável que o profissional da construção civil domine as mais recentes tecnologias, como o BIM, para se tornar ainda mais competitivo. Para os novos profissionais (recém-formados) que buscam o primeiro emprego é primordial que saiam das instituições de ensino o mais atualizados possível. Com isso, surge a seguinte pergunta: será que os alunos estão se formando com o conhecimento e domínio do que há de mais novo no mercado referente a projetos?

O objetivo geral deste trabalho é apresentar as ferramentas de ensino atual nas disciplinas de desenho técnico civil, observar as opiniões dos alunos do IFPE - Campus Caruaru sobre esse tema e potencializar o uso da tecnologia BIM para o ensino do desenho técnico civil.

Por fim, espera-se que estre trabalho gere um novo olhar sobre a importância do ensino do desenho técnico civil a partir da utilização das novas tecnologias, evitando, assim, uma frustação dos estudantes com relação ao curso ao se depararem com um mercado de trabalho que exija essa nova tecnologia no ato de projetar.

\section{FERRAMENTAS PARA A ELABORAÇÃO DO DESENHO TÉCNICO CIVIL}

\section{Desenho Técnico com a Prancheta}

Os modos de desenvolver um projeto até a década de 1980 eram idênticos aos praticados na década de 1940, com o uso da prancheta e das demais ferramentas manuais de desenho técnico (SOUZA; BIANCHI; SILVA, 2018) (Figura 1).

\section{Figura 1 - Aula de desenho, em 1940}

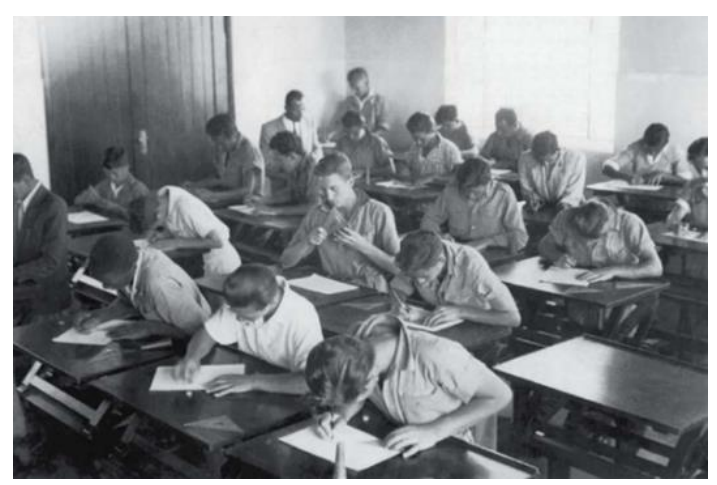

Fonte: Coleção Elétrica, n. 2 (2012).

Ainda hoje, o ensino do desenho técnico com o uso da prancheta para esboçar um projeto faz parte do cronograma educacional dos cursos de engenharia, arquitetura e cursos técnicos em edificações, mesmo com a evolução dos recursos computacionais disponíveis. Como pode se observar na Figura 2, a estrutura de uma sala de desenho técnico ainda é mantida; notase que a principal diferença, se comparada com a sala da Figura 1, é a inclusão da régua paralela 
nas pranchetas, que facilita, agiliza e melhora a precisão na elaboração do desenho técnico.

Figura 2 - Laboratório de Desenho Técnico

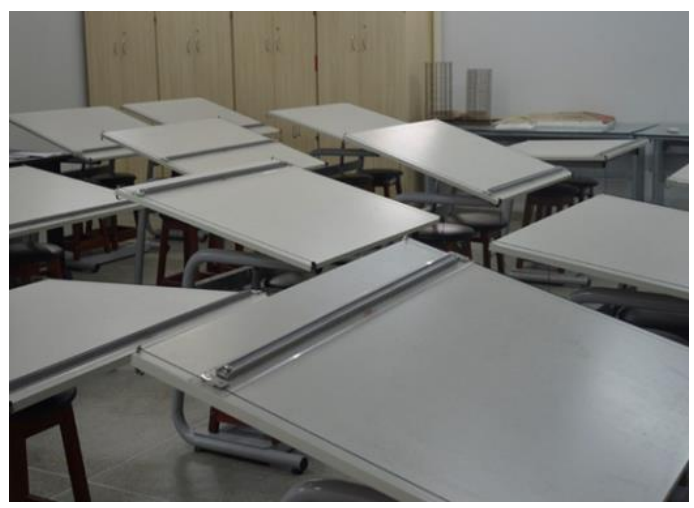

Fonte: IFCE (2017).

Para a elaboração do desenho técnico com esse método são necessários os seguintes equipamentos: prancheta profissional, que serve de apoio para a folha; banco para o desenhista; escalímetro; esquadro; régua; lápis ou lapiseira; borracha; compasso; e fita crepe para a fixação da folha na prancheta. Conhecer o modo correto de utilização dos materiais é fundamental para se esboçar um desenho com mais detalhes, proporcionando mais realidade ao projeto.

O desenho técnico com o uso da prancheta propicia um bom dinamismo às aulas, além de o aluno desenvolver habilidades para representar as formas gráficas em seu projeto, tendo uma melhor concepção espacial (tridimensional). Porém, alunos que não possuem uma boa habilidade e coordenação para manusear os equipamentos de desenho acabam por terem diversas dificuldades durante a disciplina.

\section{Desenho Técnico com o Sistema CAD}

Com o avanço tecnológico e as maiores exigências do mercado de trabalho (por exemplo: projetos ricos em detalhes e prazos curtos), foram desenvolvidas ferramentas computacionais de desenho técnico para suprir tais necessidades.

De acordo com Schodek et al. (2007), em 1980 foi iniciada a aplicação da tecnologia para o desenvolvimento de projetos arquitetônicos e complementares, através de um sistema designado CAD (Desenho Assistido por Computador).

Ayres Filho e Scheer (2007) afirmam que o CAD que melhor se adequou ao potencial de hardware da época foi o CAD geométrico, que possibilita a elaboração de desenhos no plano bidimensional (2D) virtual. Entretanto, esse sistema apresenta algumas limitações, pois pessoas que não são habituadas com esse modo de representação (2D) têm grande dificuldade para interpretar o que foi desenhado.

Com isso, surgiu o CAD 3D, no qual se começa a representar o desenho técnico de modo tridimensional (3D) para facilitar a interpretação de um projeto. À medida que se observou a necessidade de melhoramentos, o sistema CAD foi implementando novas funções (RUSCHEL; BIZELLO, 2011).

No Brasil, o sistema CAD ainda é muito representativo para a elaboração de projetos. A maiorias das redes de ensino (técnico e superior) relacionadas à construção civil utiliza nas disciplinas de desenho arquitetônico, instalações hidráulicas e elétricas a elaboração de projetos em CAD. Assim, essas redes de ensino, além do laboratório de desenho técnico, implementaram um laboratório de informática com o software CAD instalado nos equipamentos, conforme a Figura 3.

Figura 3 - Laboratório de CAD

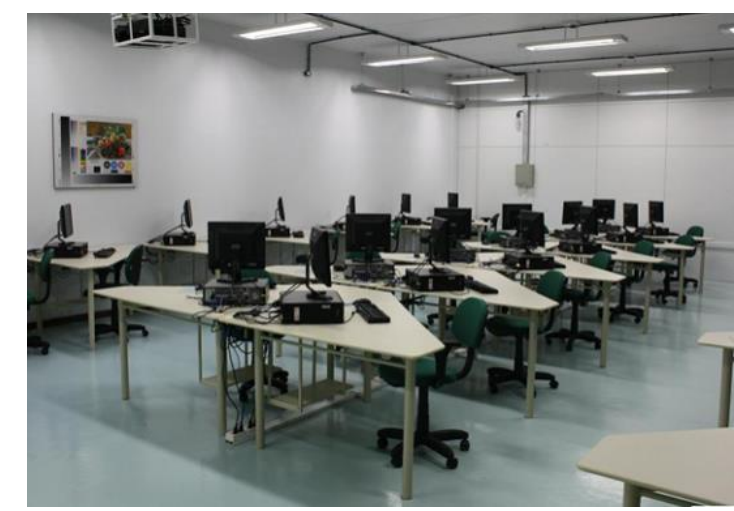

Fonte: UCS (2011).

Entre as vantagens da utilização do sistema CAD para o ensino do desenho técnico, Righetto (1999) destaca que o emprego dessa ferramenta computacional é um recurso para o desenvolvimento cognitivo espacial dos sujeitos, sendo imprescindível à inserção dos alunos no mercado de trabalho. 


\section{Desenho Técnico com o Sistema BIM}

Nos últimos anos, há um aumento no interesse da indústria de Arquitetura, Engenharia e Construção (AEC) pelo uso do sistema BIM. Essa procura ocorre por causa dos benefícios e economia de recursos durante o projeto, planejamento e construção de edificações $\quad$ (VOLK; $\quad$ STENGEL; SCHULTMANN, 2013).

Ainda, o sistema CAD, em muitos casos, não está sendo suficiente para a representação e gerenciamento de projetos, que estão ficando cada vez mais complexos. Alguns dos fatores para essa ocorrência é o fato de os projetos serem realizados de forma independente e apresentados separadamente por projetistas das mais diversas áreas (arquitetônica, de estrutura, de instalações prediais, etc.). Nesse caso, geralmente, não ocorre o compartilhamento de informações para o desenvolver dos projetos em paralelo. Além do mais, esses projetos, com as devidas documentações, excluem uma série de informações acerca de especificações de materiais, orçamento, cronograma, etc. (INFOCOMM, 2011).

No sistema BIM, ao se projetar um modelo do edifício virtualmente, através de ferramentas tridimensionais, toda a informação necessária à representação gráfica, à quantificação de trabalhos, à análise construtiva e aos tempos de mão de obra, desde a fase inicial do empreendimento até o seu termino, ou até mesmo ao processo de manutenção e desmontagem ao final do ciclo de vida útil, encontra-se no esquema a seguir, conforme a Figura 4 (FERREIRA; CORCINI; ALEIXO, 2019).

Figura 4 - BIM no ciclo de vida da construção

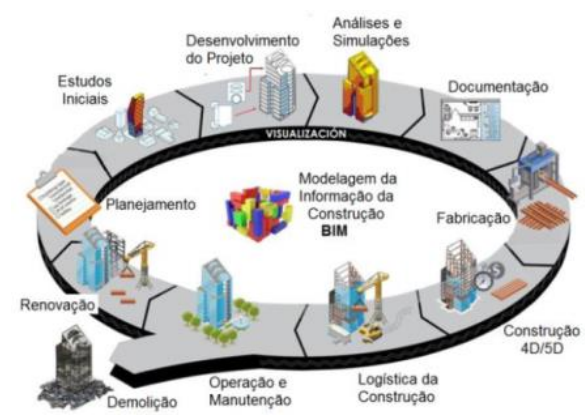

Fonte: Ferreira, Corcini e Aleixo (2019).
De acordo com Netto (2020), o conceito de BIM reúne a ideia de se construir uma edificação virtual antes de construí-la realmente (fisicamente). As informações necessárias para se construir a edificação estão no modelo digital produzido ao se projetar com esse conceito. Logo, o modelo digital torna-se um banco de dados que permite fazer a simulação real de um protótipo da construção real.

Nunes e Leão (2018) destacam que, ao contrário do sistema CAD, os elementos que representam os objetos (como: janela, porta, entre outros) armazenam informações técnicas particulares dos materiais de construção. Com isso, a ferramenta tem capacidade de além de fornecer cortes e elevações, tabelas de esquadrias, acabamentos, áreas, ela também oferece estimativas de cálculo e custos da obra. Com isso, é possível acompanhar precisamente $\mathrm{o}$ andamento de um projeto desde a fase inicial até a representação final com modelagem 3D.

Com relação à elaboração de um projeto utilizando o sistema BIM, diversos benefícios são atingidos, como: visualização antecipada e mais precisa de um projeto; correções automáticas de baixo nível quando mudanças são feitas no projeto; geração de desenhos 2D precisos e consistentes em qualquer etapa do projeto; colaboração antecipada entre múltiplas disciplinas de projeto; verificação facilitada das intenções de projetos; extração de estimativas de custo durante a etapa de projeto; e incrementação da eficiência energética e a sustentabilidade (EASTMAN et al., 2014).

Estudos realizados por alguns autores, como Campos Neto et al. (2012) e Nunes e Leão (2018), demonstram que o sistema BIM pode reduzir o tempo de elaboração de projetos de engenharia. Uma pesquisa realizada por Bryde, Broquetas e Volm (2013), a partir da compilação de 35 estudos de casos, em diversos países, durante dois anos - no período de 20082010 -, quantificou os efeitos positivos e negativos da utilização da tecnologia BIM (Tabela 1). 
Tabela 1 - A classificação dos critérios de sucesso do uso do BIM

\begin{tabular}{llllllll}
\hline & \multicolumn{3}{c}{ Efeitos positivos } & \multicolumn{3}{c}{ Efeitos negativos } \\
\hline Critério de sucesso & $\begin{array}{l}\text { Total de } \\
\text { instâncias }\end{array}$ & $\begin{array}{l}\text { Número } \\
\text { total de } \\
\text { projetos }\end{array}$ & $\begin{array}{l}\text { \%otal do } \\
\text { to projetos }\end{array}$ & $\begin{array}{l}\text { Total de } \\
\text { instâncias }\end{array}$ & $\begin{array}{l}\text { Número } \\
\text { total de } \\
\text { projetos }\end{array}$ & $\begin{array}{l}\text { dotal } \\
\text { de } \\
\text { projetos }\end{array}$ \\
\hline $\begin{array}{l}\text { Redução ou controle } \\
\text { de custos }\end{array}$ & 29 & 21 & $60,00 \%$ & 3 & 2 & $5,71 \%$ \\
$\begin{array}{l}\text { Redução ou controle } \\
\text { de tempo }\end{array}$ & 17 & 12 & $34,29 \%$ & 4 & 3 & $8,57 \%$ \\
$\begin{array}{l}\text { Melhoria de } \\
\text { comunicação }\end{array}$ & 15 & 13 & $37,14 \%$ & 0 & 0 & $0,00 \%$ \\
$\begin{array}{l}\text { Melhoria de } \\
\text { coordenação }\end{array}$ & 14 & 12 & $34,29 \%$ & 7 & 3 & $8,57 \%$ \\
$\begin{array}{l}\text { Aumento ou controle } \\
\text { de qualidade }\end{array}$ & 13 & 12 & $34,29 \%$ & 0 & 0 & $0,00 \%$ \\
$\begin{array}{l}\text { Redução de risco } \\
\text { negativo }\end{array}$ & 8 & 6 & $17,14 \%$ & 2 & 1 & $2,86 \%$ \\
$\begin{array}{l}\text { Esclarecimento de } \\
\text { escopo }\end{array}$ & 3 & 3 & $8,57 \%$ & 0 & 0 & $0,00 \%$ \\
$\begin{array}{l}\text { Melhoria } \\
\text { organizacional }\end{array}$ & 2 & 2 & $5,71 \%$ & 2 & 2 & $5,71 \%$ \\
$\begin{array}{l}\text { Problemas de } \\
\text { software }\end{array}$ & 0 & 0 & $0,00 \%$ & 9 & 7 & $20,00 \%$ \\
\hline
\end{tabular}

Fonte: Adaptada de Bryde, Broquetas e Volm (2013).

Conforme a Tabela 1, o benefício relatado com mais frequência está relacionado à redução de custos e ao controle ao longo do ciclo de vida do projeto. Economias de tempo significativas também foram relatadas. Os efeitos negativos se concentraram principalmente em relação ao uso do software BIM, podendo ser resolvidos com a melhor formação dos funcionários envolvidos e atividades de engajamento dos stakeholders (BRYDE; BROQUETAS; VOLM, 2013).

Com relação à estrutura física para implantação do desenho técnico civil com a utilização do sistema BIM, conforme já destacado no item anterior, as redes de ensino implementaram um laboratório de informática para o ensino do CAD. Logo, essa mesma estrutura pode ser utilizada, sendo apenas necessárias a aquisição e a instalação de um software BIM nos computadores.

\section{METODOLOGIA}

De acordo com Gil (2008), a pesquisa pode ser classificada como exploratória, quanto aos seus objetivos, pois busca entender o que os estudantes acham sobre as ferramentas utilizadas no ensino do desenho técnico civil. A pesquisa também pode ser classificada do ponto de vista do planejamento como levantamento de campo; e do ponto de vista da abordagem como predominantemente quantitativa, pois visa a mensurar os dados obtidos.

Após revisão bibliográfica acerca dos tipos de ferramentas utilizadas para o desenho técnico, o estudo foi desenvolvido a partir de um questionário formulado com questões fechadas, de natureza exploratória.

O questionário foi aplicado aos discentes do curso técnico em edificações do Instituto Federal de Pernambuco (IFPE) - Campus Caruaru. Conforme o período da realização da pesquisa, as turmas do curso técnico de edificações que participaram foram as seguintes: na modalidade do subsequente, o $2^{\circ}$ e $4^{\circ}$ períodos; na modalidade do integrado, o $3^{\circ}$, $5^{\circ}$ e $7^{\circ}$ períodos. $\mathrm{O} 1^{\circ}$ período do integrado ficou de fora da pesquisa devido aos alunos ainda não terem cursado nenhuma disciplina profissionalizante.

A aplicação do questionário ocorreu de modo virtual (on-line), por causa do momento 
de isolamento social que o país atravessa (pandemia da Covid-19), através do aplicativo Google Forms, no período de 16 de setembro de 2020 a 04 de outubro de 2020. As questões contidas no formulário foram divididas em dois blocos.

O primeiro bloco contém oito questões acerca dos conhecimentos dos alunos sobre o sistema BIM, sendo as seguintes perguntas:

1. Quais das ferramentas de desenho técnico civil você conhece?

2. Qual seu nível de domínio de desenho técnico com o sistema BIM?

3. Caso você saiba utilizar um software do sistema BIM, onde/como você aprendeu?

4. Você considera importante o desenvolvimento em 3D de um projeto ou se consideram o $2 \mathrm{D}$ suficiente?

5. Você acha importante para o projetista conhecer o quantitativo de material necessário para a obra?

6. $\mathrm{Na}$ elaboração de um projeto (Ex.: arquitetônico), o que você acha sobre desenvolver uma planta em 2D e automaticamente ter o projeto em 3D, além de ter automaticamente o quantitativo de materiais da edificação?

7. Uma residência é composta de projeto arquitetônico, estrutural, hidrossanitário e elétrico, onde cada um pode ser desenvolvido por profissionais diferentes. Com isso, pode ser encontrado interferência entre os projetos. $\mathrm{O}$ que você acha sobre a utilização de um software que realiza a compatibilização e identifica os problemas?

8. Qual das ferramentas, abaixo, para desenho técnico civil você acha mais importante para uso profissional?

O segundo bloco contém quatro perguntas acerca do que os alunos acham sobre a implementação do ensino do sistema BIM, sendo as seguintes perguntas:

1. Você gostaria que sua instituição de ensino adotasse medidas para o ensino do sistema BIM?

2. Como você gostaria que o ensino do sistema BIM fosse implementado?

3. Você preferiria aprender de modo isolado (apenas o BIM para desenho arquitetônico, depois apenas BIM para instalações elétrica, e assim sucessivamente) ou integrado (um único módulo que envolva um projeto que aborde todas as disciplinas)?
4. $\mathrm{Na}$ aprendizagem do sistema BIM, você preferiria aprender através da realização de um projeto de modo individual ou em grupo?

Por fim, serão discutidas algumas recomendações para a inserção de um método de ensino do sistema BIM. Serão levadas em consideração as respostas dos estudantes do segundo bloco do formulário, sendo destacados conteúdo programático e possíveis plataformas de ensino.

\section{RESULTADO DO QUESTIONÁRIO}

Com o fim da coleta de dados via formulário, observou-se que 64 alunos do curso técnico em edificações do IFPE - Campus Caruaru responderam o questionário, sendo $51,6 \%$ (33 alunos) do subsequente e 48,4\% (31 alunos) do integrado. A distribuição dos alunos por período é apresentada no Gráfico 1 .

\section{Gráfico 1 - Alunos x Períodos}

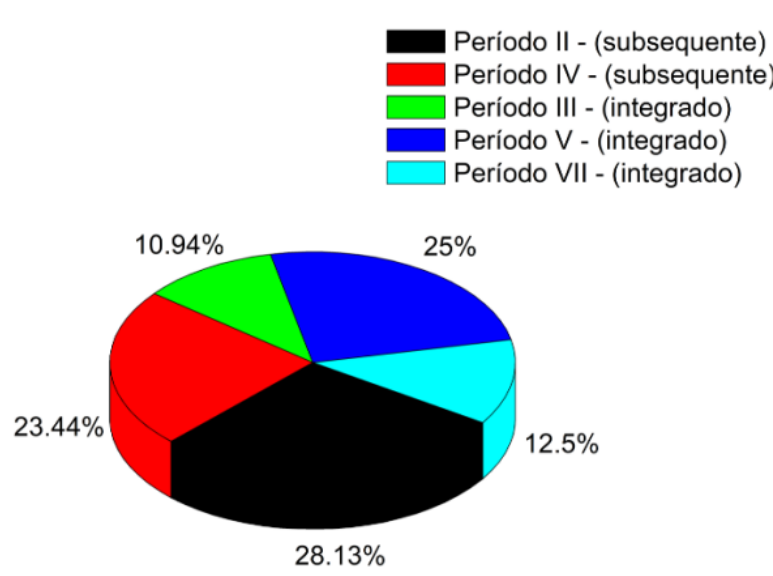

Fonte: elaborado pelos autores.

\section{Primeiro bloco de questões: conhecimentos dos alunos sobre o sistema BIM}

Com relação às ferramentas utilizadas para o desenho técnico civil (primeira pergunta do questionário), a maioria dos alunos, 48,44\%, responderam que conhecem a prancheta e o sistema CAD; já $31,25 \%$ dos estudantes afirmaram conhecer todas as ferramentas, incluindo o sistema BIM, que não está inserido na matriz curricular; por fim, $20,31 \%$ responderam que conhecem apenas a 
prancheta, porcentagem obtida devido às respostas dos alunos dos períodos iniciais do curso, nos quais os estudantes ainda não aprenderam a realizar os desenhos com o sistema CAD.

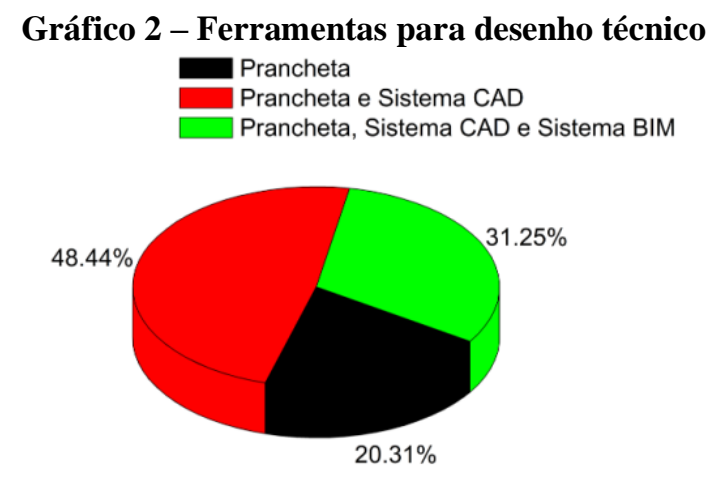

Fonte: elaborado pelos autores.

Aos alunos que responderam conhecer o sistema BIM (20 alunos) foram realizados dois questionamentos; o primeiro sobre o nível de domínio (pergunta 3 do questionário), (Gráfico 3A); e o segundo acerca do modo como aprenderam (pergunta 2 do questionário) (Gráfico 3B).

\section{Gráfico 3 - Domínio e aprendizagem em BIM}

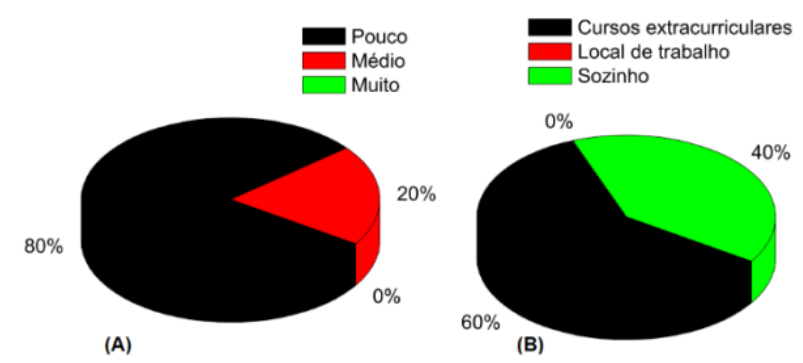

Fonte: elaborado pelos autores.

Observa-se, no Gráfico 3(A), que 80\% dos alunos que responderam conhecer o sistema BIM têm pouco domínio; apenas 20\% têm um domínio mediano; e nenhum deles tem muito domínio. Com relação ao Gráfico 3(B), ainda no que diz respeito a esses 20 estudantes, $60 \%$ responderam que aprenderam através de cursos extracurriculares; $40 \%$ deles apreenderam sozinho, ou seja, sem nenhum tutor; e nenhum deles aprendeu no local de trabalho - o que seria uma possibilidade, visto que alguns estudantes estão em processo de estágio em empresas de engenharia e arquitetura.
São apresentadas, conforme a Tabela 2, as perguntas 4 e 5 do questionário e seus respectivos dados obtidos, com relação à elaboração de projetos e seus detalhes necessários.

Tabela 2 - Detalhamento de projetos

\begin{tabular}{ll}
\hline Perguntas & Dados obtidos \\
\hline & $\bullet 95,3 \%$ responderam que é \\
& importante o desenvolvimento de \\
Pergunta 4 & um projeto tanto em 3D quanto em \\
& $\mathrm{D} ;$ \\
& $\bullet 4,7 \%$ responderam que um apenas \\
& é o suficiente. \\
\hline & $\bullet 96,9 \%$ responderam que é \\
& importante o projetista conhecer o \\
Pergunta 5 & para realizariva de material necessário \\
& $\bullet 3,1 \%$ responderam que não é \\
& importante.
\end{tabular}

Fonte: elaborado pelos autores.

Conforme a Tabela 2, nota-se que mais de 95\% dos estudantes entrevistados acham importante a realização de projetos em 3D (pergunta 4). Algo que, na prática, realmente é importante, pois nem sempre as plantas em 2D apresentam o nível de detalhamento adequado para a execução do projeto e, para fins comerciais, o 3D esclarece como ficará aquela edificação, visto que as pessoas leigas não conseguem imaginar bem a concepção da edificação a partir de uma representação de apenas duas dimensões.

Ainda de acordo com a Tabela 2, quase todos os alunos acham importante que o profissional responsável pelo desenvolvimento do projeto conheça o quanto de material será utilizado para a realização de uma determinada obra. Na prática, isso é de fundamental importância, pois, por exemplo, um projetista de instalações hidrossanitárias tem que apresentar ao cliente o quantitativo de material para a execução daquele projeto, servindo de base para a criação de um orçamento.

A seguir, na Tabela 3, são informados os dados obtidos por meio das perguntas 6 e 7, que têm como objetivo questionar sobre recursos tecnológicos em software para desenho técnico civil. 
Tabela 3 - Recursos tecnológicos para o desenvolvimento do desenho técnico civil

\begin{tabular}{|c|c|}
\hline Perguntas & Dados obtidos \\
\hline Pergunta 6 & $\begin{array}{l}\text { - } 70,3 \% \text { acham muito importante a } \\
\text { realização de um projeto em } 2 \mathrm{D} \text { e ter } \\
\text { automaticamente o } 3 \mathrm{D} \text {, além do } \\
\text { quantitativo de materiais; } \\
\text { - } 28,1 \% \text { acham que é importante } \\
\text { tudo que foi descrito acima; } \\
\text { - } 1,6 \% \text { acham que é pouco } \\
\text { importante tudo que foi descrito } \\
\text { acima. }\end{array}$ \\
\hline Pergunta 7 & $\begin{array}{l}\text { - } 75 \% \text { acham que é muito } \\
\text { importante a utilização de um } \\
\text { software que realize } \\
\text { compatibilização de projetos; } \\
\text { - } 25 \% \text { acham que é importante tudo } \\
\text { que foi descrito acima; } \\
\text { - } 0,0 \% \text { acha que é pouco importante } \\
\text { tudo que foi descrito acima. }\end{array}$ \\
\hline
\end{tabular}

Fonte: elaborado pelos autores.

Conforme a Tabela 3, em ambas as perguntas (6 e 7), a maioria achou muito importante ou importante recursos tecnológicos que apresentam ao projetista o projeto em $3 \mathrm{D}$, quantitativo de material e a compatibilização de projetos, sendo este último extremamente necessário para se evitar interferência entre os projetos, pois, no mercado de trabalho, os projetos que compõem um edificação (arquitetônico, estrutural, elétrico, entre outros) podem ser realizados por profissionais diferentes.

Por fim, a última pergunta do primeiro bloco (pergunta 8) indagou aos estudantes entrevistados sobre qual a ferramenta mais importante para a elaboração do desenho técnico civil. Sendo assim, 64,1\% (41 alunos) dos estudantes informaram que acham o sistema CAD; 31,3\% (20 alunos) acham o sistema BIM; e 4,7\% (3 alunos) acham a prancheta. Logo, observa-se que apenas aqueles estudantes que responderam conhecer o sistema BIM acham que este é o melhor. A maioria adirmou ser o sistema CAD o mais importante, principalmente pelo fato de não conhecerem o sistema BIM.
Segundo bloco de questões: sobre a implementação do ensino do sistema BIM

No segundo bloco foi avaliado o modo de implementação do ensino do sistema BIM. A primeira pergunta foi se os alunos gostariam que a instituição de ensino adotasse medidas para o ensino do desenho técnico utilizando o sistema BIM. Após o fim da pesquisa, observou-se que $100 \%$ dos alunos responderam "sim" para essa indagação. Nota-se o interesse dos alunos pela aprendizagem dessa ferramenta, mesmo a maioria achando que o sistema CAD (já ensinado nas disciplinas curriculares) é o mais importante para o desenvolvimento do desenho técnico civil. Acredita-se que essa unanimidade na vontade de aprender o sistema BIM foi despertada pelo interesse na utilização de um programa que traz algumas vantagens, como: 3D automático do projeto, quantitativo de materiais e compatibilização de projetos.

$\mathrm{Na}$ segunda pergunta desse bloco foi questionado aos estudantes como seria implementado o ensino do sistema BIM; o resultado está apresentado no Gráfico 4.

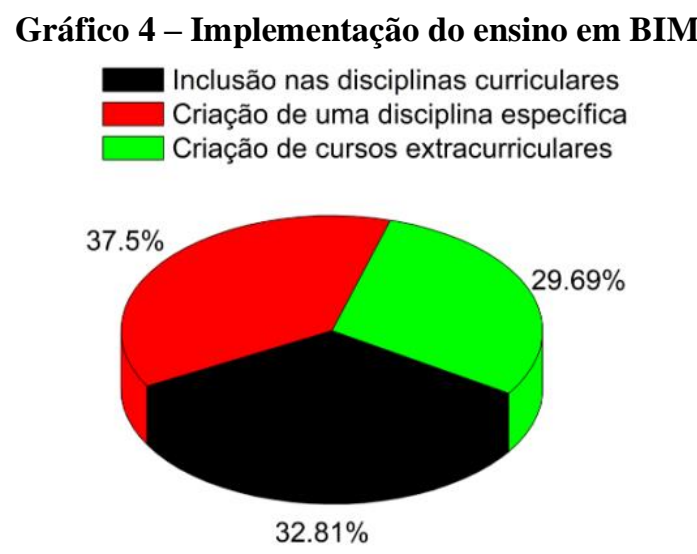

Fonte: elaborado pelos autores.

Constatou-se, de acordo com o Gráfico 4, que o resultado foi bastante divergente, sendo que as alternativas apresentaram porcentagens próximas umas das outras. Entretanto, a alternativa mais votada entre os estudantes foi a de "criação de uma disciplina específica" para o ensino do sistema BIM.

Por fim, as duas últimas perguntas desse bloco (perguntas 3 e 4) estão relacionadas às 
características para a escolha de uma metodologia de ensino. Os resultados obtidos são expostos no Gráfico 5.

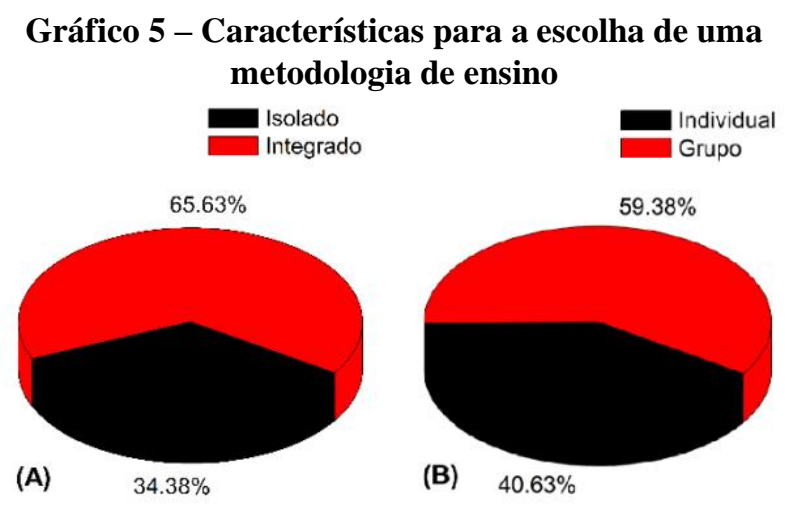

Fonte: elaborado pelos autores.

De acordo com o Gráfico 5(A), observa-se que a $65,63 \%$ dos estudantes optaram pela aprendizagem do sistema BIM de modo integrado; ou seja, um único módulo que envolva um projeto que aborde todas as disciplinas, ao invés do modo isolado, em que consistiria na aprendizagem do sistema BIM apenas com relação ao projeto arquitetônico, depois outro módulo utilizando o sistema BIM para projeto estrutural e assim sucessivamente. Logo, nota-se que os alunos acham melhor aprender através de um único projeto todo o conteúdo.

Por fim, de acordo com o Gráfico 5(B), a maioria dos alunos acham melhor aprender o sistema BIM desenvolvendo um projeto em grupo ao invés de individualmente. A escolha dessa opção é bastante vantajosa. Segundo Araújo et al. (2016), o trabalho em grupo promove entre os estudantes o respeito pelas opiniões diversas; além disso, estes devem aprender a entrar em consensos.

\section{RECOMENDAÇÕES PARA A IMPLEMENTAÇÃOO DO ENSINO DO DESENHO TÉCNICO CIVIL COM O SISTEMA BIM}

As instituições de ensino estão sempre realizando adaptações nos currículos de seus cursos, a fim de se atualizar com as tecnologias atuais. Um exemplo disso é a implementação do ensino do sistema BIM nos cursos técnicos em Edificações, assim como nos de Arquitetura e Engenharia Civil.

Checcucci (2019) realizou uma pesquisa sobre dissertações e teses brasileiras acerca do BIM. Um dos tópicos de sua pesquisa foi analisar as teses e dissertações brasileiras sobre ensino-aprendizagem de BIM nos anos de 2013 a 2018.

Segundo a autora, foram encontrados 12 trabalhos que tratam de ensino-aprendizagem de BIM durante esse período, sendo quatro de doutorado e oito de mestrado. Com isso, podese observar que o número de trabalhos ainda é pequeno com relação à demanda de ensinoaprendizagem do sistema BIM.

Considerando as respostas dos estudantes no segundo bloco do questionário, verifica-se que a maioria optou pela criação de uma disciplina específica - sendo essa disciplina conduzida de modo integrado (um projeto que aborde todas as disciplinas referentes a edificações) e em grupo. Logo, sugere-se a implementação de uma disciplina que já consta em alguns cursos de Arquitetura, Engenharia Civil e técnico em Edificações, conhecida como Projeto Integrador.

$O$ Projeto Integrador consiste na elaboração de um trabalho que resulte em um projeto final, de acordo com diretrizes estabelecidas pelos professores. Essa disciplina seria cursada no último período do curso, pois os alunos teriam todos os conhecimentos sobre as etapas de um projeto de edificações - desde o levantamento planialtimétrico, passando pelo projeto de arquitetura e chegando aos projetos complementares (estrutural, elétrico e hidrossanitário).

$\mathrm{Na}$ primeira unidade da disciplina, seriam ensinadas as principais ferramentas para a elaboração de um projeto utilizando o sistema BIM. A segunda unidade seria destinada ao desenvolvimento de um projeto completo de edificações de um pavimento (devido a ser um curso técnico) por parte dos alunos, contemplando assim a opinião mais votada pelos alunos na terceira pergunta do segundo bloco.

Como a disciplina trata do desenvolvimento de um projeto completo no sistema BIM realizado pelos alunos, em grupos, poderia ser utilizada a metodologia de ensino 
conhecida como Aprendizagem Baseada em Projetos (ABP). De acordo com Bender (2014), a ABP é um modelo de ensino que consiste em possibilitar que os estudantes confrontem as questões e os problemas do mundo real que consideram significativos, determinando como abordá-los e, então, agindo de forma cooperativa em busca de soluções.

Logo, o referido projeto a ser desenvolvido poderia ocorrer do seguinte modo: o professor disponibilizaria uma planta do terreno com as devidas dimensões, curvas de níveis e localização na cidade. A partir disso, fazendo uso da ABP, o professor simularia um cliente fictício, o qual passaria informações relevantes para definir o programa de necessidades do projeto; e, com base no plano diretor local, os grupos de alunos começariam a desenvolver os seus projetos arquitetônicos. Por fim, com o projeto arquitetônico finalizado, seriam desenvolvidos os projetos complementares (estrutural hidrossanitário e elétrico).

\section{CONSIDERAÇÕES FINAIS}

Conclui-se, por meio desta pesquisa, a respeito da necessidade de as instituições de ensino, principalmente, as profissionalizantes, sempre estarem atentas às novas tecnologias, pois o que é aprendido atualmente, possivelmente, tornar-se-á obsoleto no futuro.

Pensando nesse novo cenário de desenvolvimento de projetos de construção civil, verifica-se a importância do ensino a partir das novas ferramentas utilizadas no desenvolvimento do desenho técnico civil, a fim de que os alunos saiam preparados para o mercado de trabalho.

Através do formulário aplicado, observouse a vontade dos alunos de aprender usar essas novas ferramentas, pois $100 \%$ deles responderam que gostariam que a instituição implementasse o ensino do sistema BIM. Um problema que pode ser destacado é que a maioria dos alunos não sabem o que é o sistema BIM e os que sabem não possuem um bom domínio da ferramenta.

Por fim, é discutido como poderia ser implementada uma disciplina específica para o ensino do sistema BIM, atrelada ao método de ensino Aprendizagem Baseada em Projetos (ABP), na qual os alunos trabalhariam em conjunto, partindo da concepção do projeto arquitetônico até os projetos complementares, contribuindo assim para a formação profissional dos estudantes.

\section{REFERÊNCIAS}

ARAÚJO, W. J.; et al. Aprendizagem por problemas no ensino de engenharia. Revista Docência do Ensino Superior, v. 6, n. 1, p. 57-90, abr. 2016.

AYRES FILHO, C.; SCHEER, S. Diferentes Abordagens do Uso do CAD no Processo de Projeto Arquitetônico. In: Workshop Brasileiro de Gestão do Processo de Projetos na Construção de Edifícios. Curitiba, 2007.

BAIA, D. V. S. Uso de Ferramentas BIM para o Planejamento de Obras da Construção Civil. Brasília, 2015. Dissertação (Mestrado) Universidade de Brasília. Faculdade de Tecnologia. Departamento de Engenharia Civil e Ambiental, 2015.

BENDER, W. N. Aprendizagem Baseadas em Projetos: Educação diferenciada para o século XXI. Porto Alegre: Editora Penso, 2014.

BRASIL. Decreto n' 9.377, de 17 de maio de 2018. Dispõe Estratégia Nacional de Disseminação do Building Information Modelling no Brasil Estratégia BIM BR. 2018a.

BRASIL. Estratégia Nacional de Disseminação do Building Information Modelling - BIM. Ministério da Indústria, Comércio Exterior e Serviços - MDIC, 2018b.

BRYDE, D.; BROQUETAS, M.; VOLM, J. M. The project benefits of Building Information Modelling (BIM). International Journal of Project Management, v. 31, p. 971-980, 2013.

CAMPOS NETO, S. et al. Estudo comparativo de ferramentas computacionais que utilizam tecnologia BIM para desenvolvimento de projetos de engenharia civil. Anais... 
Congresso Brasileiro de Educação em Engenharia. Belém, 2012.

CHECCUCCI, E. S. Teses e dissertações brasileiras sobre BIM: Uma análise do período de 2013 a 2018. PARC Pesquisa em Arquitetura e Construção, Campinas, SP, v. 10, ISSN 19806809, 2019.

COLEÇÃO ELÉTRICA. As histórias e os personagens do mundo das instalações elétricas. São Paulo: Atitude Editorial, 2012.

EASTMAN, C. et al. Manual de BIM: um guia de modelagem da informação da construção para arquitetos, engenheiros, gerentes, construtores e incorporadores. Porto Alegre: Bookman, 2014.

FERREIRA, J. R.; CORCINI, M. P.; ALEIXO, H. S. P. O Ensino de Bim na Disciplina Projeto Arquitetônico. Revista de Ensino de Engenharia, v. 39, n. 2, p. 137-148, 2019.

GIL, A. C. Metodologia do Ensino Superior. São Paulo: Editora Atlas, 2008.

IFCE. Laboratório de Desenho Técnico Aplicado. 2017. Disponível em: $<$ https://ifce.edu.br/moradanova/campus_mor ada/cursos/tecnicos/concomitantes/edificacoes /fotos/laboratorios-edificacoes-ecivil/laboratorios-engenharia-civil-eedificacoes/laboratorio-de-desenho-tecnicoaplicado4.jpg/view>. Acesso em: 20 de agosto de 2020.

\section{INFOCOMM INTERNATIONAL. Building Information Modeling (BIM) Guide. InfoComm International, 2011.}

NETTO, C. C. Autodesk Revit Architeture 2020: Conceitos e Aplicações. São Paulo: Érica, 2020.

NUNES, G. H.; LEÃO, M. Estudo comparativo de ferramentas de projetos entre o CAD tradicional e a modelagem BIM. Revista de Engenharia Civil, n. 55, p. 47-61, 2018.

SCHODEK, D. et al. Steinberg, M. Digital Design and Manufacturing: CAD/CAN Aplications in INC. New Jersey: John Willey \& Sons, 2007.

RIGHETTO, A. V. D. Ensino e Aprendizagem em Desenho Técnico. Anais... XXVII Congresso Brasileiro de Ensino de Engenharia (COBENGE), Natal-RN, 1999.

RUSCHEL, R. C.; BIZELLO, S. A. Avaliação de Sistemas CAD Lives. In: KOWALTOWSKI, D. C. C. K. et al. O processo de projeto em arquitetura da teoria à tecnologia. São Paulo: Oficina de Textos, 2011.

SOUZA, D. F.; BIANCHI, E. C.; SILVA, E. A. S. A Evolução dos Métodos de Projetar Instalações Elétricas. Revista de Ensino de Engenharia, v. 37, n. 3, p. 3-8, 2018.

UCS. Laboratório de CAD/CAE/CAM. 2011. Disponível em: <https://www.ucs.br/portais/cent/laboratorios/ 14541/>. Acesso em: 20 de agosto de 2020.

VOLK, R.; STENGEL, J.; SCHULTMANN, F. Building Information Modeling (BIM) for existing buildings - literature review and futures needs. In: Automation in Construction, Elsevier, 2013. 


\section{DADOS BIOGRÁFICOS DOS AUTORES}
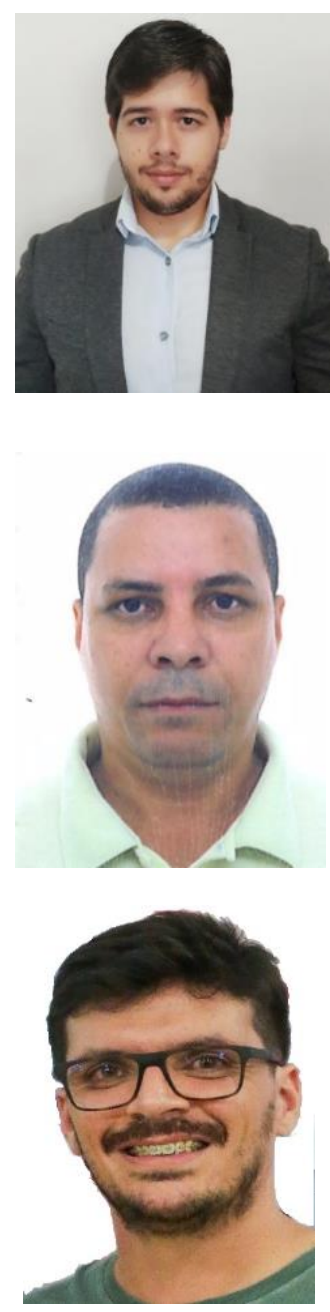

Humberto Mycael Mota Santos - Mestre em Engenharia Civil e Ambiental com ênfase em Estruturas e Materiais pela Universidade Federal de Pernambuco (UFPE, 2019). Pós-graduando em Engenharia de Segurança do Trabalho pelo Instituto Federal de Pernambuco (IFPE). Pós-graduando em Docência pelo Instituto Federal de Minas Gerais (IFMG). Graduado em Engenharia Civil pelo Centro Universitário do Vale do Ipojuca (UNIFAVIP, 2016). Atualmente é Professor no Instituto Federal de Pernambuco (IFPE), Campus Caruaru, do Curso Técnico em Edificações, além de atuar em pesquisas com foco na utilização de resíduos e subprodutos industriais e urbanos como materiais de construção.

Donisete de Oliveira - Pós-graduando em Engenharia de Segurança do Trabalho pela Faculdade Invest de Ciências e Tecnologia (MT-2019). Pós-graduando em Gestão e Perícia Ambiental pela Faculdade Invest de Ciências e Tecnologia (MT2018). Pós-graduando em Sistema de Proteção Elétrica pela Faculdade Invest de Ciências e Tecnologia (MT-2019). Graduado em Engenharia de Controle e Automação com Modalidade Eletricista pela FAC Educacional Ltda (MT-2018). Atualmente cursando o quinto período de Licenciatura em Tecnologia Educacional pela UFMT-MT.

Luiz Augusto Ferreira de Campos Viana - Mestre em Engenharia de Materiais pela Universidade Federal de Ouro Preto (UFOP - 2015). Graduado em Engenharia Industrial Mecânica pelo Centro Federal de Educação Tecnológica de Minas Gerais (CEFET-MG - 2009). Atualmente é professor do Ensino Básico, Técnico e Tecnológico do Instituto Federal de Educação, Ciência e Tecnologia de Minas Gerais (IFMG). É coordenador do curso de Bacharelado em Engenharia Mecânica do IFMG campus Avançado Arcos. Preside o Colegiado do Curso e o Núcleo Docente Estruturante do curso de Bacharelado em Engenharia Mecânica do IFMG campus Avançado Arcos. 